\title{
Biomass-Derived Nitrogen Functionalized Carbon Nanodots and Their Anti-Biofouling Properties
}

\author{
Maria K. Rybarczyk ${ }^{1, *(D)}$, Emilia Gontarek-Castro ${ }^{2} \mathbb{D}$, Karolina Ollik ${ }^{2}$ and Marek Lieder ${ }^{2}$ \\ 1 Department of Geotechnics, Faculty of Civil Engineering and Architecture, Lublin University of Technology, \\ 40 Nadbystrzycka Street, 20-618 Lublin, Poland \\ 2 Department of Process Engineering and Chemical Technology, Chemical Faculty, Gdansk University \\ of Technology, 11/12 Narutowicza Street, 80-233 Gdansk, Poland; emilia.gontarek@pg.edu.pl (E.G.-C.); \\ karolina.ollik@pg.edu.pl (K.O.); lieder@pg.edu.pl (M.L.) \\ * Correspondence: m.rybarczyk@pollub.pl
}

Citation: Rybarczyk, M.K.

Gontarek-Castro, E.; Ollik, K.; Lieder,

M. Biomass-Derived Nitrogen

Functionalized Carbon Nanodots and Their Anti-Biofouling Properties.

Processes 2021, 9, 61. https://doi.org/ $10.3390 /$ pr9010061

Received: 8 December 2020 Accepted: 25 December 2020 Published: 29 December 2020

Publisher's Note: MDPI stays neutral with regard to jurisdictional clai$\mathrm{ms}$ in published maps and institutional affiliations.

Copyright: (C) 2020 by the authors. Licensee MDPI, Basel, Switzerland. This article is an open access article distributed under the terms and conditions of the Creative Commons Attribution (CC BY) license (https:// creativecommons.org/licenses/by/ $4.0 /)$.

\begin{abstract}
The prevalence of the antibiotic resistant bacteria remains a global issue. Cheap, sustainable and multifunctional antibacterial membranes are at the forefront of filtrating materials capable of treating multiple flow streams, such as water cleansing treatments. Carbon nanomaterials are particularly interesting objects shown to enhance antibacterial properties of composite materials. In this article, amino-functionalized, photoluminescent carbon nanodots (CNDs) were synthesized from chitosan by bottom-up approach via simple and green hydrothermal carbonization. A chemical model for the CNDs formation during hydrothermal treatment of chitosan is proposed. The use of urea as an additional nitrogen source leads to the consumption of hydroxyl groups of chitosan and higher nitrogen doping level as pyridinic and pyrrolic $\mathrm{N}$-bonding configurations in the final carbonaceous composition. These functionalized carbon nanodots that consist of carbon core and various surface functional groups were used to modify the commercially available membranes in order to enhance their anti-biofouling properties and add possible functionalities, including fluorescent labelling. Incorporation of CNDs to membranes increased their hydrophilicity, surface charge without compromising membranes integrity, thereby increasing the factors affecting bacterial wall disruption. Membranes modified with CNDs effectively stopped the growth of two Gramnegative bacterial colonies: Klebsiella oxytoca (K. oxytoca) and Pseudomonas aeruginosa (P. aeruginosa).
\end{abstract}

Keywords: carbon nanodots; anti-biofouling properties; sustainable materials; chitosan; urea

\section{Introduction}

Various carbon-based starting materials, such as soot [1], carbohydrates [2-5], activated carbons [6,7], graphene oxide and graphite [8,9] have been reported in recent years as precursors to luminescent [10] carbon-based nanomaterials using straightforward oxidizing conditions at elevated temperatures. Chitosan, an abundant material in nature, has also been reported as the precursor for the synthesis of carbon dots [11]. It is a biocompatible polymer [12] with amino groups present on its surface that can be a source of nitrogendoped carbon dots. Some of the synthesis methods are followed by a specific chemical treatment like oxidation by mineral acids to tune the photoluminescent [13] properties and improve the water solubility of the carbon dots. The advantage of using chitosan is the ability to obtain nitrogen-doped carbon dots in a one-step [14], high yield synthesis [15] without complex and time-consuming treatment by other compounds.

These nanomaterials have been proposed as alternatives to their conventionally used counterparts (e.g., semiconductor quantum dots) and carry a variety of benefits such as enhanced biocompatibility and smaller sizes [16,17]. These so-called carbon dots (CDs) are generally described as nanocrystalline (graphitic) or amorphous in nature, pseudospherical, and generally are smaller than $10 \mathrm{~nm}$ in diameter [18]. 
A broad family of carbon spherical nanomaterials includes, but is not limited to, graphene quantum dots (GQDs), described as a nanometer-scale graphene derivative where quantum confinement [19] and edge effects $[20,21]$ introduce a band gap. They have been reported to be comparable [16] to CDs and have similar dimensions, photoluminescence properties, surface characteristics, and were shown to be biologically applicable [22]. There exists a continuum of species, starting with single-layer GQDs [22,23], moving to multilayer GQDs $[24,25]$ and finally to CDs [26,27], all of which can have similar dimensions and structure but generally differ in their height profiles determined by atomic force microscopy (AFM). Due to these similarities as well as the initial synthesis precursors and conditions reported for the production of CDs $[8,28,29]$ and GQDs $[9,22,30]$, there is often no clear distinction between these nanomaterial classes, especially when comparing multilayer GQDs to CDs [31].

So far, CDs have been explored for biomedical applications [32] with effective antibacterial properties leading to elimination of multitude of bacterial species via surface-induced interactions, e.g., via cationic charges disrupting bacterial membranes [33]. Recently, GQDs have also attracted attention in the field of membrane technologies and their applications in separation processes [34]. Membrane-based technologies are extensively used for water treatment and water purification in microbial fuel cell, micro-/ultra-/nano-filtration and reverse osmosis. The initial adhesion of bacteria on membranes at the beginning of the filtration process develops biofilm that reduces membrane performance [35-37] by diminishing the permeate quality and the life span of the membrane.

For an anti-microbial approach, several modifications have been investigated including composite membrane preparation or coating the surface with biocides such as silver nanoparticles [38], copper nanoparticles [39] or titanium dioxide [16], while anti-adhesion capability is closely related to the surface properties. It has been reported that membranes with hydrophobic, positively charged and rough surfaces are more likely to disrupt biofilm formation [40].

However for anti-adhesion the modification of surface properties do not prevent biofouling completely, hence for biofouling mitigation it is crucial to combine anti-adhesion and anti-microbial capability of the surfaces [41,42].

The attachment and growth of microbial cells on the surface depends on a number of factors: van der Waals attraction, hydrophobicity of the cells and surface electrostatic charges. The prevention of biofilm formation can be divided into two ways: (i) reducing the adhesion of bacteria, and (ii) killing already attached bacteria [43].

Herein, we report a robust and efficient method for bottom-up CNDs synthesis by one-pot hydrothermal treatment of dissolved chitosan at $180{ }^{\circ} \mathrm{C}$.

Hydrothermal treatments were carried with or without additional nitrogen source (urea) to check the effect of nitrogen doping on the final structure, and physicochemical, antibacterial properties of CNDs. With a passivated surface, we hypothesized the obtained CNDs would show good antibacterial activity due to their large surface-to-volume ratio and high cationic surface charge stemming from amine groups [16]. Next, we assessed the feasibility of incorporating prepared CNDs into commercial membranes to form hybrid anti-adhesive and antibacterial materials. The antimicrobial properties of CNDs were carried out on two bacterial families: K. oxytoca and P. aeruginosa.

\section{Materials and Methods}

\subsection{Chemicals}

Chitosan (medium molecular weight and deacetylation degree $81 \%$ ) was used as precursor to produce CNDs. Urea, chitosan and acetic acid were purchased from SigmaAldrich (Poznan, Poland). All solutions were prepared using distilled water.

\subsection{Synthesis of Carbon Dots}

In this research, two kinds of CNDs were prepared. The first sample was obtained from mixing $1 \mathrm{~g}$ chitosan, $6 \mathrm{~mL}$ of $99.7 \% \mathrm{CH}_{3} \mathrm{COOH}$, and $10 \mathrm{~mL}$ of $\mathrm{H}_{2} \mathrm{O}$. This resulting 
mixture was sonicated for $0.5 \mathrm{~h}$ at room temperature and then the solution was placed in a glass inlet sealed in a Teflon autoclave and maintained at $180{ }^{\circ} \mathrm{C}$ for $18 \mathrm{~h}$ (p 10 bar). This sample was named CS180. The second sample was prepared by adding $1 \mathrm{~g}$ of chitosan to a mixture of $6 \mathrm{~mL}$ of $99.7 \% \mathrm{CH}_{3} \mathrm{COOH}, 10 \mathrm{~mL} \mathrm{H}_{2} \mathrm{O}, 200 \mathrm{mg}$ of urea. The mixture was sonicated for $0.5 \mathrm{~h}$ at room temperature and then the solution was placed in a glass inlet sealed in a Teflon autoclave and maintained at $180{ }^{\circ} \mathrm{C}$ for $18 \mathrm{~h}$ ( $\mathrm{p} \sim 10 \mathrm{bar}$ ). The second sample was named CSU180. In order to remove large particles/aggregates, the synthesized dark brown solution was centrifuged at $10.000 \mathrm{rpm}$ for $10 \mathrm{~min}$, and the supernatant was filtered through a $0.22 \mu \mathrm{m}$ filter membrane.

\subsection{Incorporation of CNDs into Membranes}

In this research, the commercial cation exchange membranes CMI-7000 (Membranes International INC, Ringwood, NJ, USA) were used. CNDs were introduced into activated membranes surface by a dip-coating method and maintained in the CNDs solution for $24 \mathrm{~h}$, at ambient temperature. Afterward, membranes were dried in an air atmosphere. In order to ensure the incorporation of CNDs, each membrane was immersed in distilled water which supernatant was further tested for the released concentration of CNDs using UV-Vis spectroscopy (UV-2600, Shimadzu, Kyoto, Japan).

\subsection{Antimicrobial Activity Tests}

For antimicrobial activity tests, all bacteria were cultured overnight at $37{ }^{\circ} \mathrm{C}$. The overnight bacterial cell culture was diluted 1:100 in 1/5 LB without and with the same concentrations of CNDs for all tested bacterial cultures and then inoculated into the Petri dish plates (Costar, Corning, CN, USA) with $100 \mu \mathrm{L} /$ well. The inoculated Petri dish plates were incubated for $1-5$ days at $28^{\circ} \mathrm{C}$ without shaking.

\subsection{Characterization}

Zeta-potential was determined using Malvern Zetasizer (Software v7.02 PSS0012-33 EN-JP, Malvern Instruments Ltd., Malvern, UK). The optical properties were defined using $\mathrm{UV}-\mathrm{Vis}$ and fluorescence spectroscopies. UV-Vis absorption spectra were recorded on a Shimadzu UV-Vis Spectrophotometer (UV 2600). The photoluminescence (PL) measurements were carried out at room temperature using a photoluminescence spectrometer LS-50B (PerkinElmer, Waltham, MS, USA) equipped with a xenon discharge lamp as an excitation source and a R928 photomultiplier as a detector. Fluorescence spectra were recorded at different excitation wavelengths in the range of 250-350 nm. The morphology and structure of CNDs were measured using an atomic force microscope NanoScope V (Veeco, Plainview, NY, USA) and a high-resolution transmission electron microscope (HRTEM). HRTEM images were recorded on a field emission electron microscope (JEOL JEM-2100F, 200 kV FE (field emission), Tokyo, Japan). Functional groups of CNDs were determined by X-ray photoelectron spectroscopy (XPS, PREVAC Sp. z o. o. Rogow, Poland) and Fourier-transform infrared spectroscopy (FTIR, Thermo Scientific Instrument Co., Boston, MA, USA). XPS images were obtained with an MX-650 electron analyzer from the Gammadata Scienta company. Electrons were excited using monochromatic X-rays in which the anode was $\mathrm{Mg} / \mathrm{Al}$. Fourier transform infrared spectra of CNDs were recorded using by Thermo Nicolet 8700 spectrometer (Thermo Scientific Instrument Co., Boston, MA, USA). The wettability of the CNDs modified membranes were evaluated using a goniometric technique in the pendant drop mode, with a video based optical contact angle meter OCA 15, Dataphysics, Germany.

\section{Results and Discussion}

\subsection{Surface Functional Groups and Formation of CNDs}

To confirm the presence of surface functional groups the FTIR and XPS spectra of $\mathrm{CNDs}$ were analyzed. The clusters of CS180 contain a large proportion of $\mathrm{C}=\mathrm{O}$ and $-\mathrm{OH}$ groups, which favor agglomeration through strong hydrogen bonding. The CNDs derived 
from chitosan and urea, CSU180 also contain-OH groups, but the surface concentration of the -OHs is much lower due to their condensation reactions with urea leading to amides formation. The hydrogen bonding in amides is less efficient than for $-\mathrm{OH}$ containing molecules, which probably accounts for missing cluster formation in the case of CSU180.

The FTIR spectra of CS180 and CSU180 samples are shown in Figure 1. The broad, convoluted bands at ca. $3000-3500 \mathrm{~cm}^{-1}$ are assigned to hydroxyl groups stretching vibration. The two sharp absorbance bands at 1572 and $1418 \mathrm{~cm}^{-1}$ presumably stem from the stretching of $\mathrm{C}=\mathrm{C}$ bonds in the aromatic region and from the $\mathrm{C}-\mathrm{OH}$ bending mode, respectively. Besides, the stretching vibration peaks of the $\mathrm{C}-\mathrm{N}$ bonds (possibly amines) at circa $1000 \mathrm{~cm}^{-1}$ are clearly shown. When comparing the spectra of CSU180 with CS180, one can notice two additional bands at 1288 and $1675 \mathrm{~cm}^{-1}$ plus a weak shoulder at ca. $1720 \mathrm{~cm}^{-1}$. The presence of urea in the thermally treated acidic solution of chitosan could result in chemical reactions, which influence the composition and morphology of the final carbonaceous material. One can envisage either decomposition of urea or its condensation with chitosan. It was shown that the former process, probably through ammonia release, allows obtaining high doping level of nitrogen in a product, mainly as pyridinic and pyrrolic N-bonding configurations [44]. The condensation reaction, however, leads to a polymer-like material followed by carbonization and formation of CNDs. The mentioned condensation is well-known to proceed between urea and anomeric center of glucose in the presence of acidic catalyst $[45,46]$. The products of reaction can be both asymmetrical ureides as well as symmetrical urea-linked disaccharides. This reaction causes the consumption of hydroxyl groups of chitosan. The presented FTIR results seem to reveal remnants of this condensation in the form of the vibration bands, which we assign to $\mathrm{C}=\mathrm{O}$ stretching in $-\mathrm{NHCO}-\left(1675 \mathrm{~cm}^{-1}\right)$ and at the CNDs edges $\left(1720 \mathrm{~cm}^{-1}\right)$. The band at $1288 \mathrm{~cm}^{-1}$ was assigned to in-plane vibration of $\mathrm{C}-\mathrm{N}$ and $\mathrm{N}-\mathrm{H}$ groups of the bound amides.

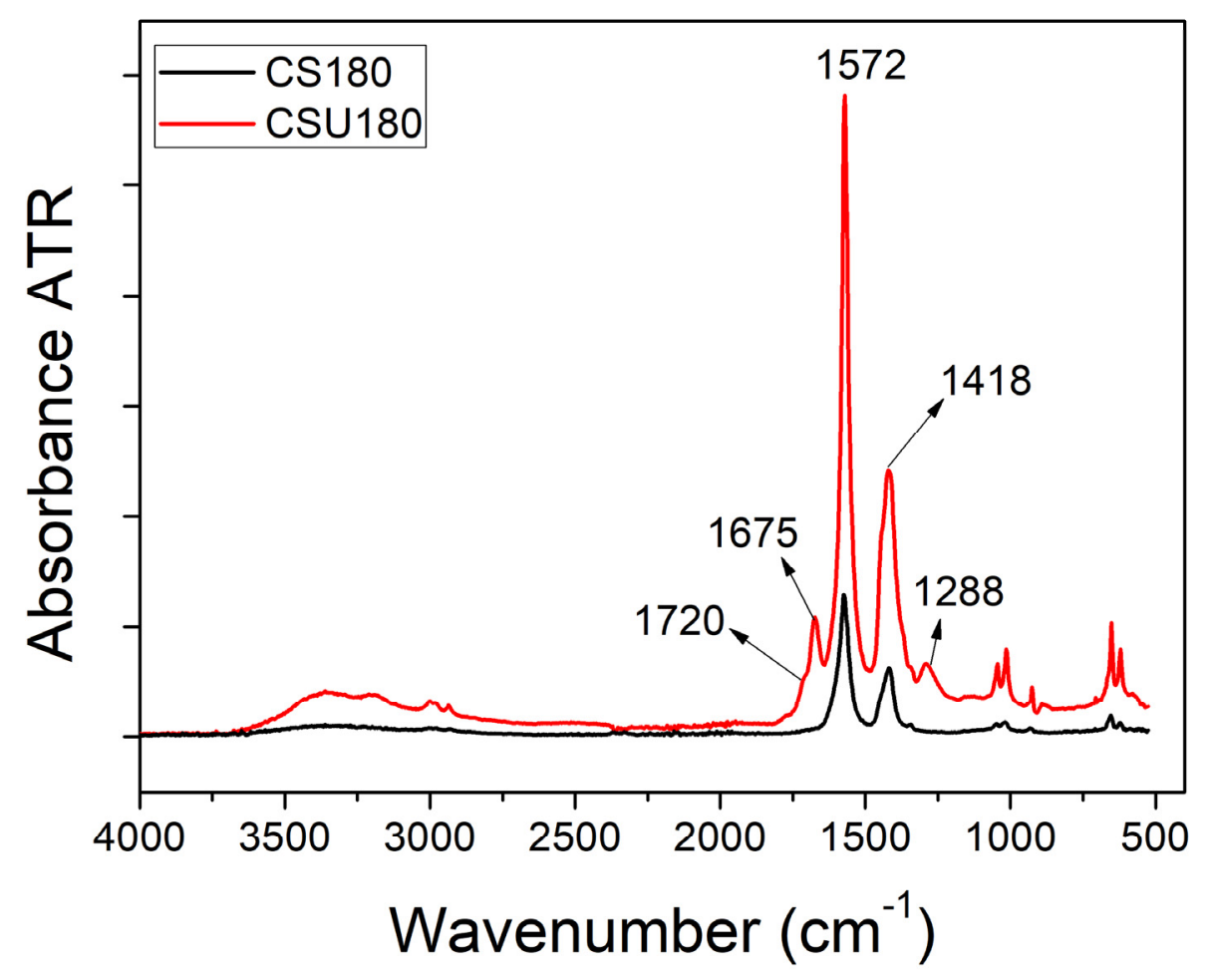

Figure 1. FTIR spectra of CS180 (marked in black) and CSU180 (marked in red).

The surface functional groups generated on the CNDs surface by the hydrothermal carbonization of chitosan precursor were analyzed by high-resolution XPS (Figure 2). As a representative example, Figure 2 shows the $\mathrm{C} 1 \mathrm{~s}, \mathrm{~N}$ 1s and $\mathrm{O}$ 1s surface-level spectra 
and the peak-fitting for the CS180 sample. The C 1s spectrum was deconvoluted to four signals at 284.7, 286.0, $287.4 \mathrm{eV}$. The first, dominant C 1s peak at $284.7 \mathrm{eV}$ stems from graphitic carbon. The other samples with urea (Figure S1,) also reveal that band, which, however, is significantly stronger than that of CS180. In the case of the second signal, two bonds contribute to its intensity; $\mathrm{C}-\mathrm{N}$ and $\mathrm{C}-\mathrm{O}$ in $\mathrm{C}-\mathrm{OH}$. The third signal could be attributed to the presence of the carbonyl groups. The presence of these oxygenated groups is confirmed by the $\mathrm{O} 1 \mathrm{~s}$ spectra, in which two signals are identified at 531.3 and $532.2 \mathrm{eV}$ (Figure 2, O1s; Figure S2) [47]. The former signal corresponds to $\mathrm{O}=\mathrm{C}$ groups, whereas the peak at $533.2 \mathrm{eV}$ is mainly attributed to -O-C-groups. The $\mathrm{N} 1 \mathrm{~s}$ spectra (Figure $2 \mathrm{~N} 1 \mathrm{~s}$, Figure S3) are deconvoluted to the dominant peaks at around 398.7-399.1 eV corresponding to pyridinic-type nitrogen, $400.1-400.2 \mathrm{eV}$ ascribed $\mathrm{N}-\mathrm{H}$ in amine and amide, and the last peak at around 401.3-401.6 eV assigned to protonated nitrogen atoms bound to three $\mathrm{C}$ atoms in the bulk of a carbon [48].
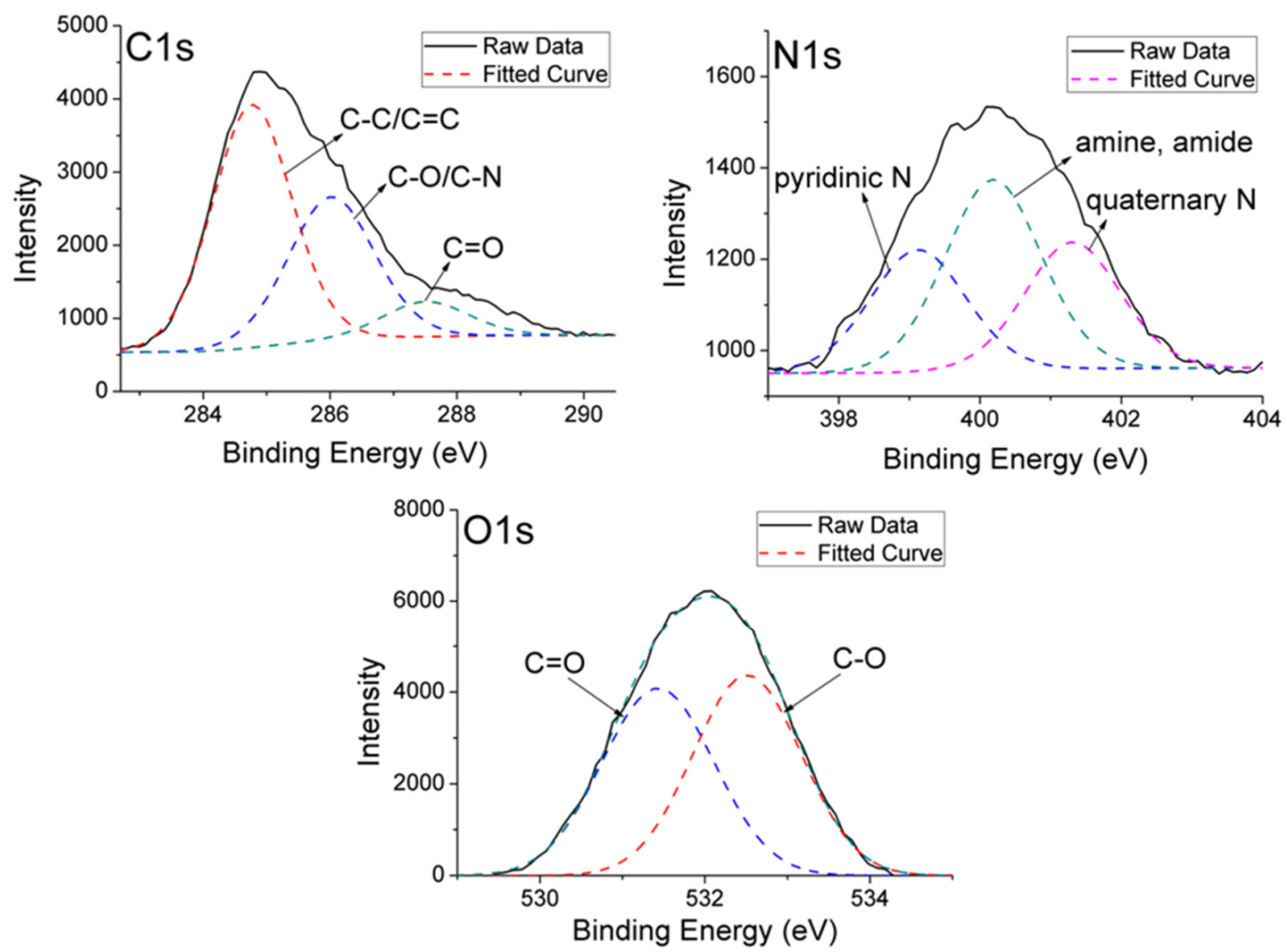

Figure 2. XPS of C 1s, N 1s and O1s surface-level spectra of CS180.

The surface atomic concentrations of $\mathrm{C}, \mathrm{O}$, and $\mathrm{N}$ were derived from the corresponding peak areas of the XPS spectra and are summarized in Table 1. The hydrothermal treatment of chitosan precursors generates CNDs with the oxygen surface concentration of ca. $20 \%$. Moreover, the sample obtained with urea has the largest amount of nitrogen with an atomic concentration of $10.3 \%$ on the CNDs surface.

Table 1. Elemental composition of CNDs.

\begin{tabular}{cccc}
\hline Sample & C (\%) & O (\%) & N (\%) \\
\hline CS180 & 72.5 & 20.0 & 7.5 \\
\hline CSU180 & 73.1 & 16.6 & 10.3 \\
\hline
\end{tabular}


As data in Table 2 show, an increase in nitrogen concentration on the CSU180 surface is mainly due to higher content of the amine/amide groups, and to a lesser extent to the pyridinic groups.

Table 2. Relative intensities of the N 1s bands (surface area of the bands).

\begin{tabular}{cccc}
\hline Sample & Pyridinic & Amine/Amide & Quaternary \\
\hline CS180 & $100(100) *$ & $113(156)$ & $102(103)$ \\
\hline CSU180 & $141(228)$ & $175(355)$ & $115(88)$ \\
\hline
\end{tabular}

* These base levels are set independently. The actual values are shown in Table S1.

These results agree well with those obtained from the FTIR measurements, which also show the presence of aromatic carbon, as well as $\mathrm{C}-\mathrm{N}$ bonds and abundant oxygenated functional groups.

The surface of CS180 is negatively charged at neutral pH (Table 3). This means that there are amine groups on the surface, but they are in a minority related to negatively charged surface groups, for example hydroxyl groups. In the case of CSU180 we observed positively charged surface which is caused by the presence of a secondary amine formed through the consumption of hydroxyl groups.

Table 3. Surface charge values for CNDs at neutral $\mathrm{pH}$.

\begin{tabular}{cc}
\hline Sample & Surface Charge $(\mathrm{mV})$ \\
\hline CS180 & $-14.3 \pm 1.4$ \\
\hline CSU180 & $15.6 \pm 2.8$ \\
\hline
\end{tabular}

Based on the results obtained by the spectroscopic analysis (FTIR, and XPS), we propose a revised chemical reaction model for the formation of CNDs in the presence of urea during hydrothermal carbonization of chitosan. The model is depicted in Figure 3 and compared to a standard route.

\subsection{Structural Features of CNDs}

Figure $4 \mathrm{a}$, b shows the TEM images of the synthesized CNDs. The CNDs are evenly dispersed, with strong tendency for clustering into circular aggregates for unmodified CNDs, here-forth referred as to CS180 (Figure 4a). Size distribution measurements show that the average diameter of CS180 is $9.12 \pm 0.82 \mathrm{~nm}$, while the urea-doped sample (henceforth referred as to CSU180) are much smaller with an average diameter of $1.43 \pm 0.06 \mathrm{~nm}$. The narrow size distribution and nearly spherical shape with the average height of $1.351 \pm 0.733$ is observed for the CSU180, in the AFM measurements (Figure 5).

\subsection{UV-Vis Absorption and Fluorescence Properties of CNDs}

The UV-Vis absorption spectra of both the CDs exhibit strong absorption in UV region (Figure $6, \lambda<300 \mathrm{~nm}$ ), which is assigned to $\mathrm{n}-\pi^{*}$ transitions in $\mathrm{C}=\mathrm{O}$ bonds in nonconductive species, $\mathrm{sp}^{3}$ hybrid regions. A very weak additional wave can be seen for the CSU180 dots at the wavelength around $340 \mathrm{~nm}$. It corresponds to the moved $n-\pi^{*}$ transitions, the same as the previous one, from aromatic system with heteroatoms $\mathrm{C}=\mathrm{O}$. This shift may be due to inductive influence of the adjacent nitrogen atoms [49].

Upon $290 \mathrm{~nm}$ excitation, the fluorescence quantum yields of the CNDs CSU180 and CS180 were estimated to be $17 \%$ and $13 \%$, respectively. 
A Standard hydrothermal CNDs synthesis

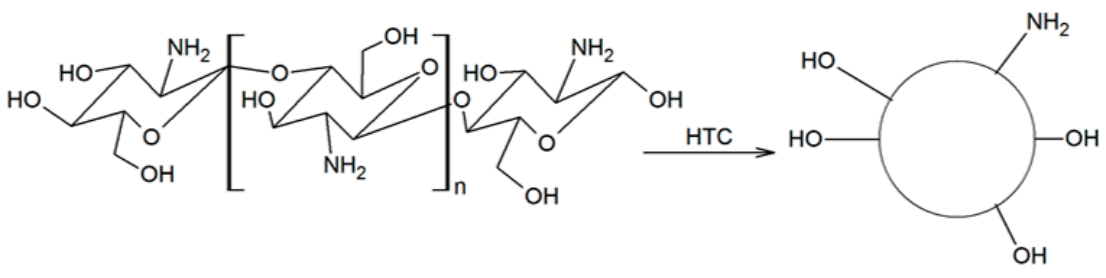

B Revised hydrothermal CNDs synthesis in the presence of urea
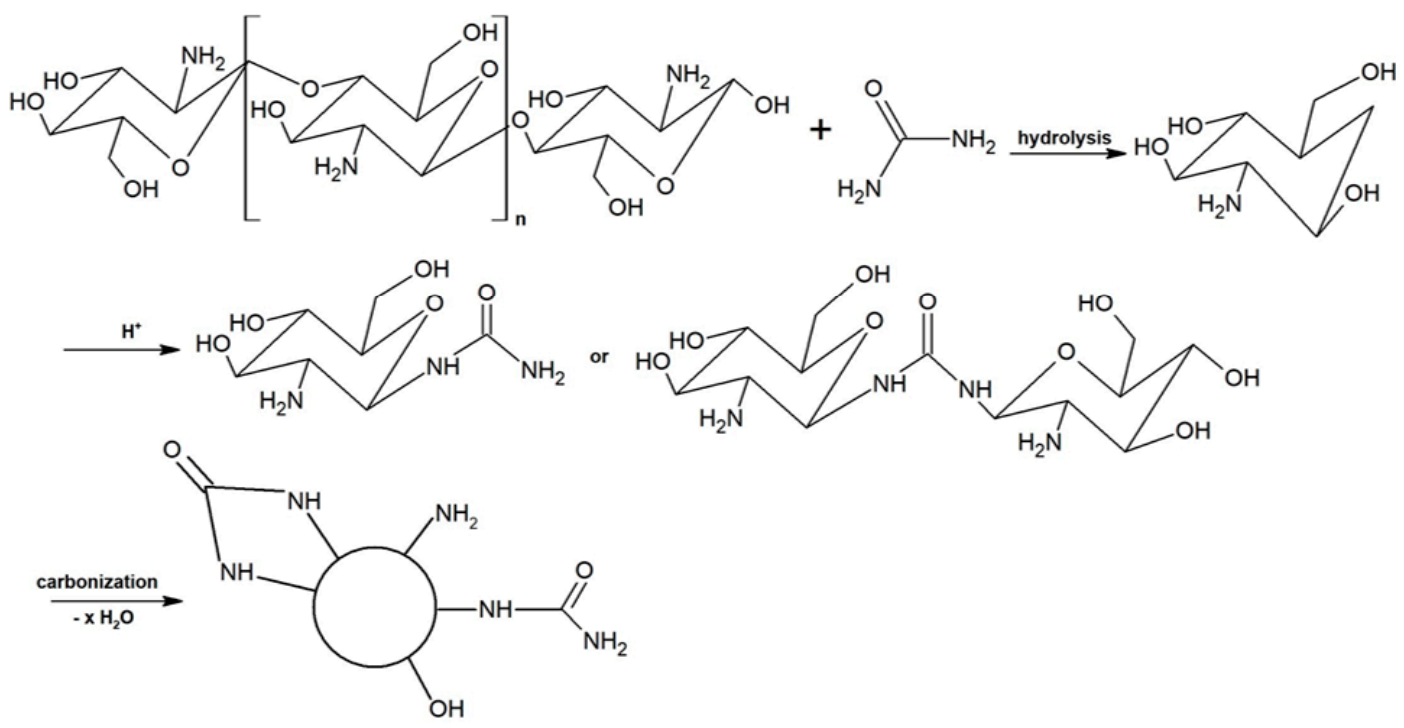

Figure 3. The proposed CNDs formation during hydrothermal carbonization of chitosan and chitosan with urea.
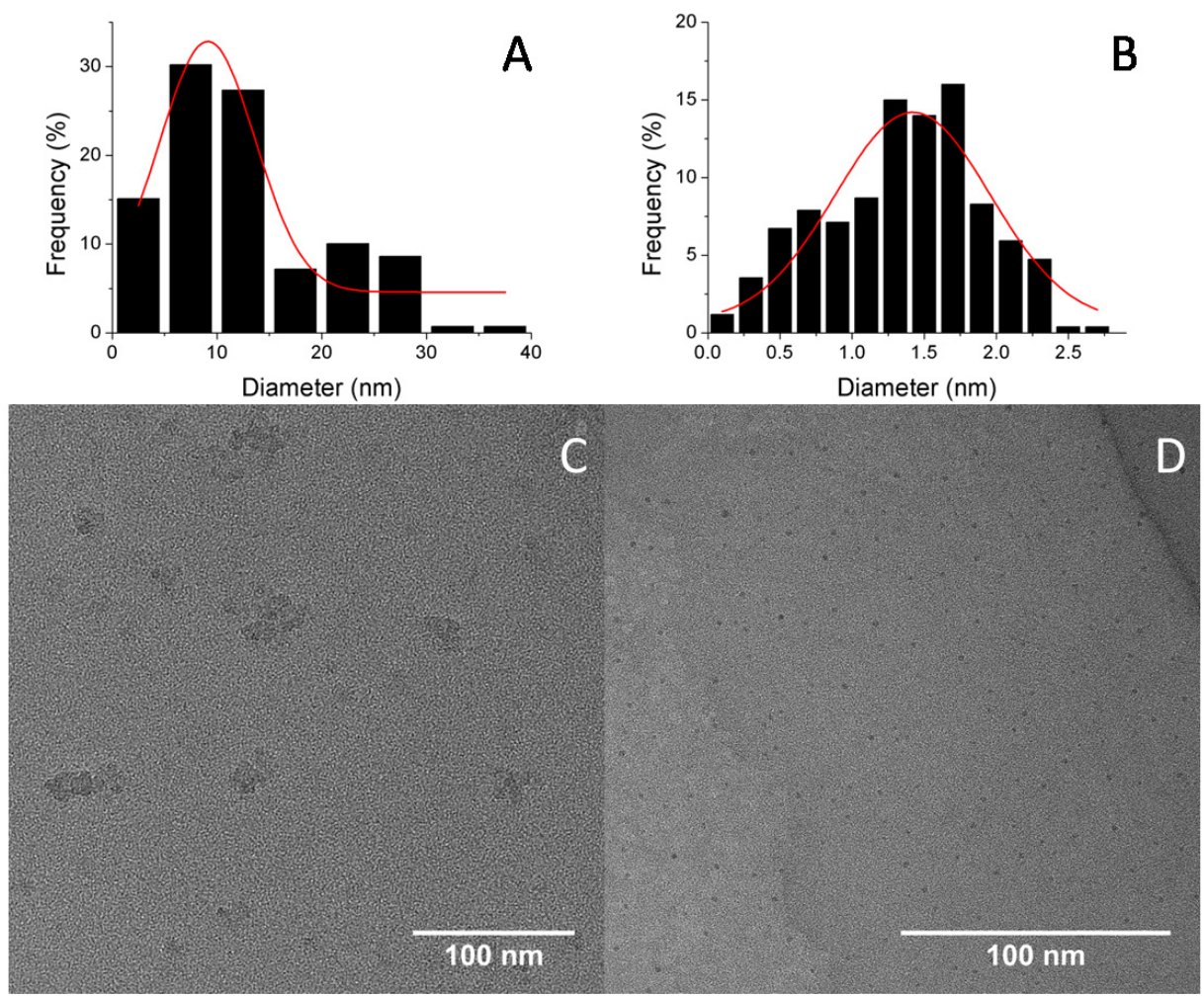

Figure 4. Size histograms (A) CS180, (B) CSU180 and the corresponding TEM images of assynthesized CNDs (C) CS180, (D) CSU180, respectively. 

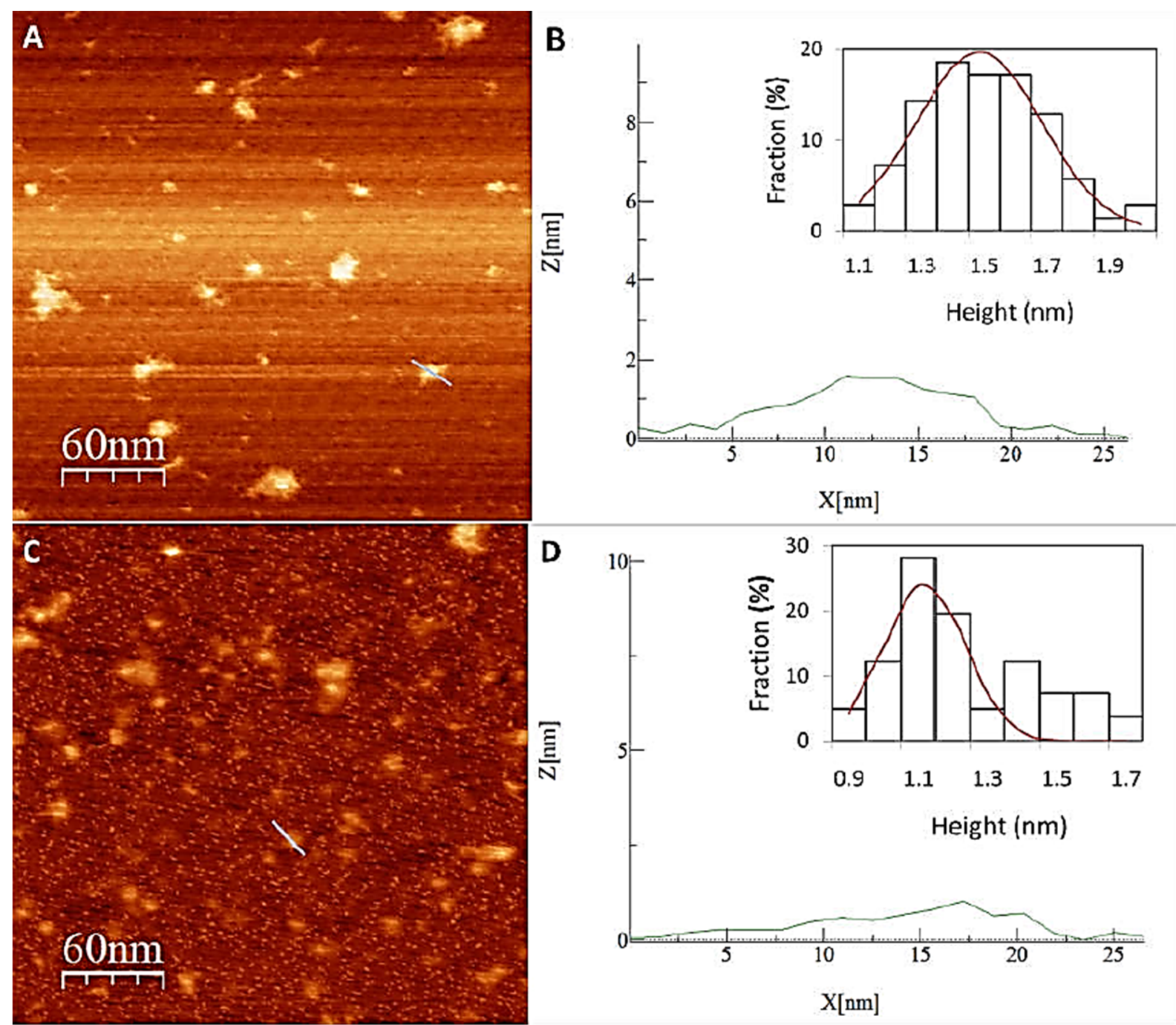

Figure 5. Atomic force microscopy (AFM) images of CS180 (A), CSU180 (C) images (B,D). The insets are the size distribution of CNDs and line profile at selected line in AFM.

Figure 7a,b illustrate the fluorescence spectra of the CS180 and CSU180 samples, respectively. As depicted, we observed the clear wavelength dependent fluorescence for both CNDs in terms of the peaks position, their intensity and shape. This effect could result from the presence of edge/core states derived from functional groups on CNDs combined with the dots-solvent interaction. The spectra for the CS180 dots are mainly determined by carboxylic acid groups that are electronically coupled with the surrounding graphene core sheets [50]. In the case of the CSU180, in addition to oxygen-based groups, amine-based groups also contribute to their surface state, either by allowing the electronic structure to be modified by the effective orbital resonance of the amine moieties and the graphene core [51], or through formation of an additional interband within the energy gap owing to p-orbital hybridization of $\mathrm{C}-\mathrm{N}$ atoms at the edge sites [52]. Here, the fluorescence is affected by the electron transfer nature, e.g., electron withdrawing and donating properties of the functional environment. The phenomenon of fluorescence red-shift could be intensified by the presence of a slowed solvation process during fluorescence emission [53], which should stronger influence the larger CS180 dots. The mechanism behind the red-shift emission properties is often associated with surface or defect states in the amorphous carbon shell of CDs near the Fermi level [54]. 


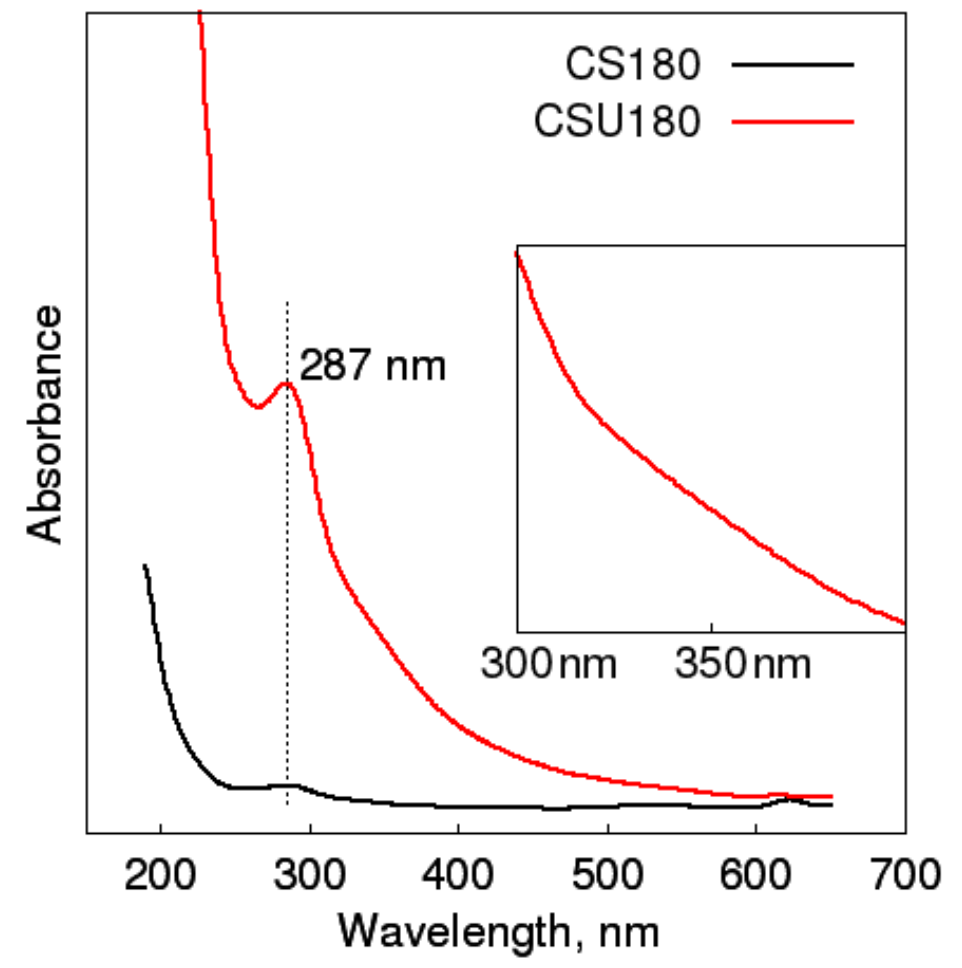

Figure 6. UV-Vis absorption spectra of CS180 (marked black) and CSU180 (marked red).
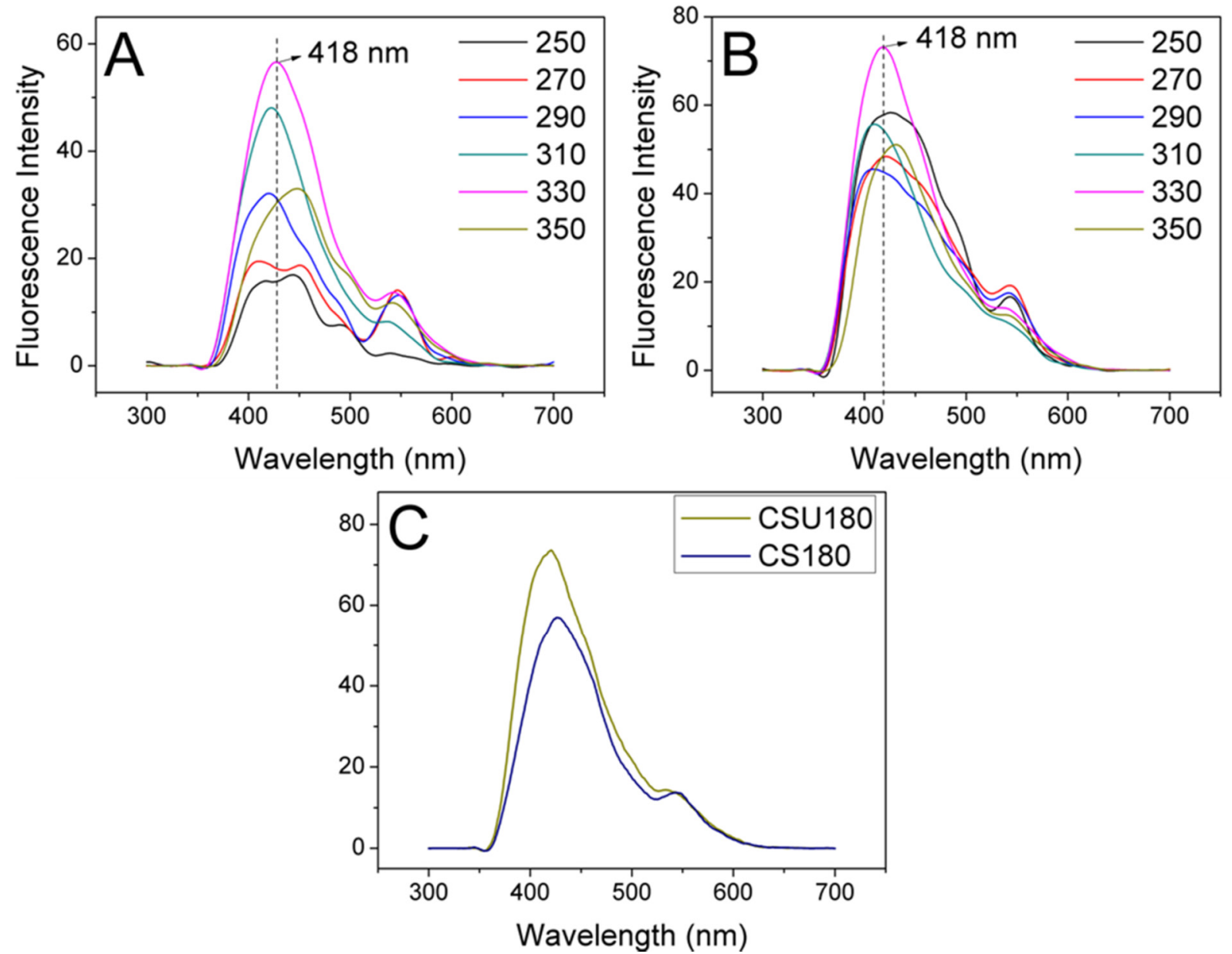

Figure 7. Fluorescence spectra of CS180 (A), CSU180 (B) and their combination at $418 \mathrm{~nm}$ (C). 


\subsection{Incorporation of CNDs into Membranes and Their Antimicrobial Properties}

In order to investigate the antimicrobial properties of the prepared CNDs, they were used to modify the commercial CMI-7000 7000 cation exchange membranes. Firstly, the hydrophilicity of modified membranes was evaluated by the contact angle (Table 4). The minimum contact angle of $24.0^{\circ}$ was obtained for CSU180 incorporated membranes (MCSU180), indicating CNDs decreased the hydrophobicity of both unmodified commercial membranes $\left(60.8^{\circ}\right)$, as well as unmodified CNDs incorporated into membranes (M-CS180) $\left(70.3^{\circ}\right)$. The contact angle values strongly depend on chemical structure and surface porosity [40]. The enhancement of hydrophilicity could affect the microbial properties of membranes, because bacterial attachment is significantly stronger to more hydrophobic surfaces [40].

Table 4. Contact angle values for unmodified membrane and membranes modified with CNDs.

\begin{tabular}{cc}
\hline Sample & Contact Angle \pm SD [ ${ }^{\circ}$ ] \\
\hline unmodified & $60.8 \pm 1.0$ \\
\hline M-CS180 & $70.3 \pm 1.2$ \\
\hline M-CSU180 & $24.0 \pm 0.9$ \\
\hline
\end{tabular}

The antibacterial tests against Escherichia coli (E. coli), P. aeruginosa and K. oxytoca were performed to determine the antibacterial properties of as-prepared samples. All of the bacterial cultures were representative of Gram-negative type of bacteria. As can be seen, after incubation, E. coli bacteria had attached and expanded on the surface of the unmodified sample (Figure 8). The results are similar for sample modified with CS180 what indicates that the CNDs treatment had no effect on the growth of $E$. coli. This behavior (in the case of sample with CSU180) can be correlated with the roughness value of the modified surface that is similar for modification with CSU180 but lower than for CS180.

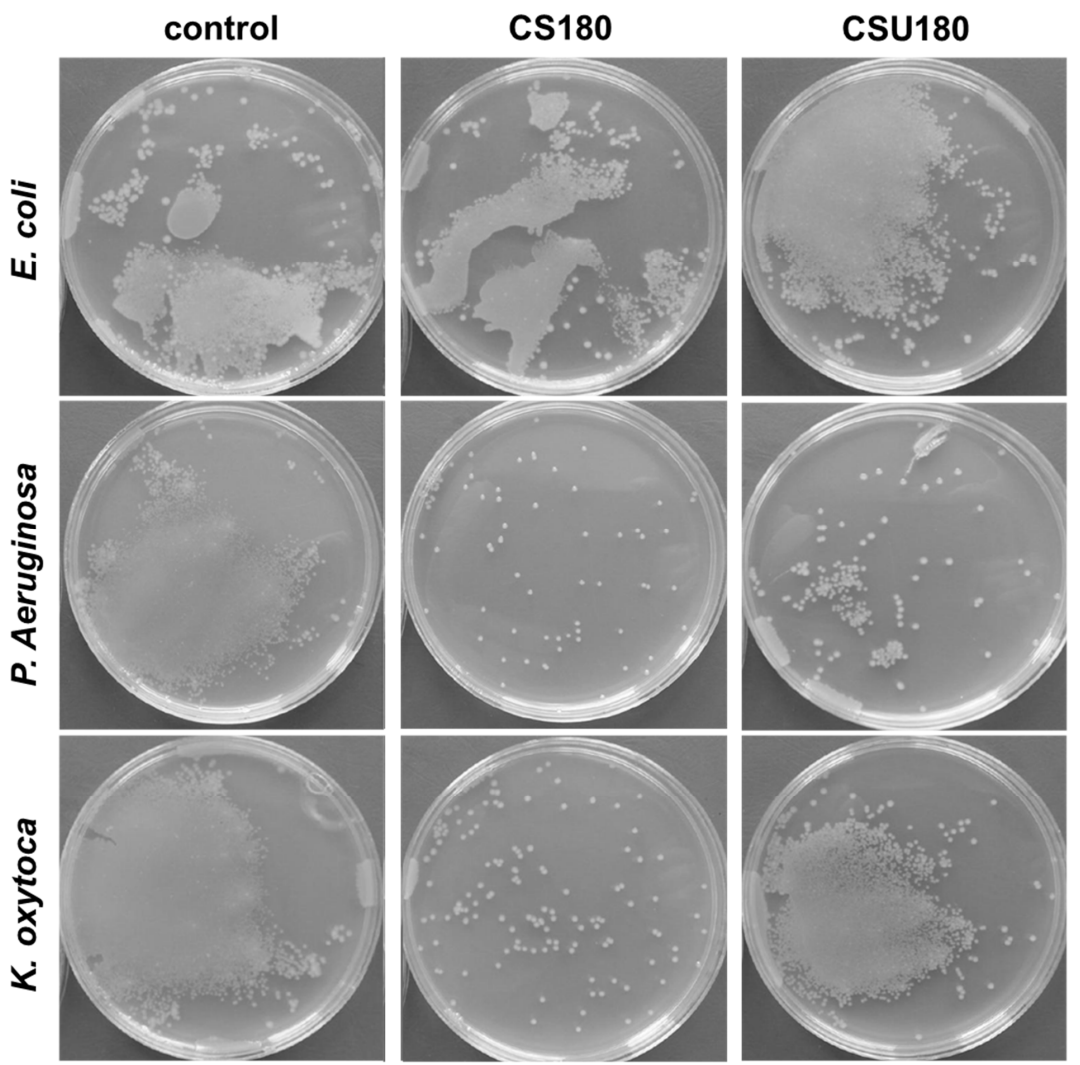

Figure 8. Microbiological studies. 
Better results have been received for P. aeruginosa bacteria tests. After incubation visible differences between modified and unmodified samples can be seen (Figure 8, Table 5). The modification with CS180 and CSU180 significantly inhibited growth of the P. aeruginosa bacteria, and the lowest activity of this bacterial culture is observed on the sample modified with CS180.

Table 5. Microbial enumeration.

\begin{tabular}{cccc}
\hline & E. coli & P. aeruginosa & K. oxytoca \\
\hline Unmodified & +++++ & +++++ & +++++ \\
CS180 & +++++ & + & + \\
CSU180 & +++++ & ++ & ++++ \\
\hline
\end{tabular}

Where + is equal $20 \%$ of the bacterial enumeration.

Similar results were obtained for K. oxytoca tests for sample with CS180 with the highest inhibition results, while for modification with CSU180 high activity of K. oxytoca is still observed.

Since all tested bacteria were Gram-negative, the surface charge and different affinity of the bacteria to the surface of the modified membrane is the key factor of inhibition. The cell wall charge of Gram-negative bacteria is strongly negative due to the presence of lipopolysaccharides as an outer layer. Therefore, it can be expected that they could easily interact with the positively charged surface via electrostatic interactions. There are some studies on the interaction between carbon dots and bacteria that indicated that the surface charge on CNDs is an important factor inhibiting growth of bacteria [45].

However, it has to be considered that bacterial growth inhibition differs not only depending on carbon dots solution used for membrane modification but also depending on the type of tested bacteria colonies. It means that as-prepared carbon dots show antibacterial selectivity. The Gram-type selective antibacterial activity of carbon dots has already been reported for example for quaternized carbon nanospheres [55] and can be explained by the difference between Gram-positive and Gram-negative bacteria concerning their structure and charge under physiological pH conditions. Interestingly, the membranes modified with CDs were ineffective in inhibiting the activity of E. coli. Even though all of the tested bacteria are gram negative they belong to different groups in terms of producing the energy-the facultative anaerobes (K. oxytoca, P. aeruginosa) and microaerophilic bacteria (E. coli) [56]. The presented results suggested that the as-prepared CDs could not inhibit the growth of microaerophilic bacteria, but it showed highly efficiency against facultative anaerobes. The selective inhibition was also demonstrated in literature for carbon nanodots obtained from Metronidazole [56]. Liu et al. established that carbon nanodots can only inhibit the growth of obligate anaerobes and the growth of facultative anaerobes, obligate aerobes or microaerophilic bacteria could not be inhibited. It was explained as a result of their different structures, and the possibility of the degradation of the macromolecule only in obligate anaerobes. Moreover, CNDs can act as oxidizing agents, which produce free radicals in microbial organisms. Further, CNDs induced membrane stress by increasing oxidative stress resulting in cell content leakage and cell death [56]. A characteristic feature of CNDs compared with functionalized nanoparticles, GQDs are more effective against microorganisms than metal nanoparticles (ranging in size from $30 \mathrm{~nm}$ to $100 \mathrm{~nm}$ ) [57].

In addition, further research on CNDs-modified membranes can help design membranes with broad-spectrum antimicrobial activity for fuel cell technology. Generally speaking, CNDs possess varied surface functional groups which can be further easily engineered by ligands or even drugs for suitable applications [55].

\section{Conclusions}

In summary, we demonstrated a facile method to synthesize amino-functionalized fluorescent carbon nanodots with antimicrobial properties by hydrothermal carbonization of chitosan. No further modification is needed in their preparation. Our work has shown that many of the properties of CNDs depend on their functionalization, including their 
optical and antibacterial properties. The as-prepared CNDs consist of an aromatic core and surface functional groups, mainly amine, that are able to inhibit the growth of some types of Gram-negative bacteria. We showed that membranes modified with CNDs stopped the growth of two Gram-negative bacterial colonies: K. oxytoca and P. aeruginosa. However, this process is complex and also depends on other parameters, such as the hydrophobicity of the membrane and its surface roughness.

Our results show that bacterial growth is inhibited upon application of CNDs, which indicates their possible use in antibacterial applications.

Supplementary Materials: The following are available online at https:/ / www.mdpi.com/2227-971 7/9/1/61/s1, Figure S1: The C1s XPS of CSU180. Figure S2: The O1s XPS of CSU180. Figure S3: The N1s XPS of CSU180. Figure S4: The C1s XPS of CS180. Figure S5: The O1s XPS of CS180. Figure S6: The N1s XPS of CS180. Figure S7: AFM studies of CS180 (A) and CSU180 (B). Table S1: Intensity of the $\mathrm{N} 1 \mathrm{~s}$ bands (surface area of the bands).

Author Contributions: Conceptualization, M.K.R.; investigation, M.K.R., E.G.-C. and K.O., writingoriginal draft preparation, M.K.R. and E.G.-C.; writing-review and editing, M.K.R. and M.L.; supervision, M.L.; project administration and funding acquisition, M.K.R. All authors have read and agreed to the published version of the manuscript.

Funding: This research was financed by the National Science Centre of Poland within the Project MINIATURA 2 no. DEC-2018/02/X/ST5/02760.

Acknowledgments: M.K. Rybarczyk would like to acknowledge the COST Action CA15107 Multicomp, supported by the COST Association (European Cooperation in Science and Technology) Dr. J.K. Wychowaniec (University College Dublin) is greatly acknowledged for his fruitful discussion and comments on publication.

Conflicts of Interest: The authors declare no conflict of interest.

\section{References}

1. Liu, H.; Ye, T.; Mao, C. Fluorescent carbon nanoparticles derived from candle soot. Angew. Chem. Int. Ed. 2007, 46, 6473-6475. [CrossRef] [PubMed]

2. Peng, H.; Travas-Sejdic, J. Simple aqueous solution route to luminescent carbogenic dots from carbohydrates. Chem. Mater. 2009, 21, 5563-5565. [CrossRef]

3. Li, H.; He, X.; Liu, Y.; Huang, H.; Lian, S.; Lee, S.T.; Kang, Z. One-step ultrasonic synthesis of water-soluble carbon nanoparticles with excellent photoluminescent properties. Carbon N. Y. 2011, 49, 605-609. [CrossRef]

4. Xu, M.; Huang, Q.; Sun, R.; Wang, X. Simultaneously obtaining fluorescent carbon dots and porous active carbon for supercapacitors from biomass. RSC Adv. 2016, 6, 88674-88682. [CrossRef]

5. Zhao, S.; Lan, M.; Zhu, X.; Xue, H.; Ng, T.W.; Meng, X.; Lee, C.S.; Wang, P.; Zhang, W. Green Synthesis of Bifunctional Fluorescent Carbon Dots from Garlic for Cellular Imaging and Free Radical Scavenging. ACS Appl. Mater. Interfaces 2015, 7, 17054-17060. [CrossRef]

6. Qiao, Z.A.; Wang, Y.; Gao, Y.; Li, H.; Dai, T.; Liu, Y.; Huo, Q. Commercially activated carbon as the source for producing multicolor photoluminescent carbon dots by chemical oxidation. Chem. Commun. 2010, 46, 8812-8814. [CrossRef]

7. Rybarczyk, M.K.; Lieder, M.; Jablonska, M. N-doped mesoporous carbon nanosheets obtained by pyrolysis of a chitosan-melamine mixture for the oxygen reduction reaction in alkaline media. RSC Adv. 2015, 5, 44969-44977. [CrossRef]

8. Zhao, Q.L.; Zhang, Z.L.; Huang, B.H.; Peng, J.; Zhang, M.; Pang, D.W. Facile preparation of low cytotoxicity fluorescent carbon nanocrystals by electrooxidation of graphite. Chem. Commun. 2008, 41, 5116-5118. [CrossRef]

9. Tadyszak, K.; Musiał, A.; Ostrowski, A.; Wychowaniec, J.K. Unraveling origins of EPR spectrum in graphene oxide quantum dots. Nanomaterials 2020, 10, 798. [CrossRef]

10. Cringoli, M.C.; Kralj, S.; Kurbasic, M.; Urban, M.; Marchesan, S. Luminescent supramolecular hydrogels from a tripeptide and nitrogen-doped carbon nanodots. Beilstein J. Nanotechnol. 2017, 8, 1553-1562. [CrossRef]

11. Briscoe, J.; Marinovic, A.; Sevilla, M.; Dunn, S.; Titirici, M. Biomass-Derived Carbon Quantum Dot Sensitizers for Solid-State Nanostructured Solar Cells. Angew. Chem. Int. Ed. 2015, 54, 4463-4468. [CrossRef] [PubMed]

12. Barra, A.; Alves, Z.; Ferreira, N.M.; Martins, M.A.; Oliveira, H.; Ferreira, L.P.; Cruz, M.M.; Carvalho, M.D.D.; Neumayer, S.M.; Rodriguez, B.J.; et al. Biocompatible chitosan-based composites with properties suitable for hyperthermia therapy. J. Mater. Chem. B 2020, 8, 1256-1265. [CrossRef] [PubMed]

13. Khan, A.; Goepel, M.; Colmenares, J.C.; Gläser, R. Chitosan-Based N-Doped Carbon Materials for Electrocatalytic and Photocatalytic Applications. ACS Sustain. Chem. Eng. 2020, 8, 4708-4727. [CrossRef] 
14. Yang, Y.; Cui, J.; Zheng, M.; Hu, C.; Tan, S.; Xiao, Y.; Yang, Q.; Liu, Y. One-step synthesis of amino-functionalized fluorescent carbon nanoparticles by hydrothermal carbonization of chitosan. Chem. Commun. 2012, 48, 380-382. [CrossRef] [PubMed]

15. Wang, L.; Li, B.; Xu, F.; Shi, X.; Feng, D.; Wei, D.; Li, Y.; Feng, Y.; Wang, Y.; Jia, D.; et al. High-yield synthesis of strong photoluminescent $\mathrm{N}$-doped carbon nanodots derived from hydrosoluble chitosan for mercury ion sensing via smartphone APP. Biosens. Bioelectron. 2016, 79, 1-8. [CrossRef] [PubMed]

16. Sciortino, A.; Cannizzo, A.; Messina, F. Carbon Nanodots: A Review-From the Current Understanding of the Fundamental Photophysics to the Full Control of the Optical Response. C-J. Carbon Res. 2018, 4, 67. [CrossRef]

17. Meng, X.; Zhang, C.; Dong, C.; Sun, W.; Ji, D.; Ding, Y. Carbon quantum dots assisted strategy to synthesize Co@NC for boosting photocatalytic hydrogen evolution performance of CdS. Chem. Eng. J. 2020, 389, 124432. [CrossRef]

18. Papaioannou, N.; Marinovic, A.; Yoshizawa, N.; Goode, A.E.; Fay, M.; Khlobystov, A.; Titirici, M.M.; Sapelkin, A. Structure and solvents effects on the optical properties of sugar-derived carbon nanodots. Sci. Rep. 2018, 8, 6559. [CrossRef]

19. Liu, Y.; Huang, H.; Cao, W.; Mao, B.; Liu, Y.; Kang, Z. Advances in carbon dots: From the perspective of traditional quantum dots. Mater. Chem. Front. 2020, 4, 1586-1613. [CrossRef]

20. Hassan, M.; Haque, E.; Reddy, K.R.; Minett, A.I.; Chen, J.; Gomes, V.G. Edge-enriched graphene quantum dots for enhanced photo-luminescence and supercapacitance. Nanoscale 2014, 6, 11988-11994. [CrossRef]

21. Tang, J.; Zhang, J.; Zhang, Y.; Xiao, Y.; Shi, Y.; Chen, Y.; Ding, L.; Xu, W. Influence of Group Modification at the Edges of Carbon Quantum Dots on Fluorescent Emission. Nanoscale Res. Lett. 2019, 14. [CrossRef] [PubMed]

22. Pan, D.; Zhang, J.; Li, Z.; Wu, M. Hydrothermal route for cutting graphene sheets into blue-luminescent graphene quantum dots. Adv. Mater. 2010, 22, 734-738. [CrossRef] [PubMed]

23. Song, L.; Shi, J.; Lu, J.; Lu, C. Structure observation of graphene quantum dots by single-layered formation in layered confinement space. Chem. Sci. 2015, 6, 4846-4850. [CrossRef] [PubMed]

24. Jindal, S.; Giripunje, S.M. An insight into electronic and optical properties of multilayer graphene quantum dots synthesized by hydrothermal approach. Synth. Met. 2018, 239, 36-42. [CrossRef]

25. Wimmenauer, C.; Scheller, J.; Fasbender, S.; Heinzel, T. Single-particle energy-and optical absorption-spectra of multilayer graphene quantum dots. Superlattices Microstruct. 2019, 132, 106171. [CrossRef]

26. Huang, J.J.; Zhong, Z.F.; Rong, M.Z.; Zhou, X.; Chen, X.D.; Zhang, M.Q. An easy approach of preparing strongly luminescent carbon dots and their polymer based composites for enhancing solar cell efficiency. Carbon N. Y. 2014, 70, 190-198. [CrossRef]

27. Keerthana, A.K.; Ashraf, P.M. Carbon nanodots synthesized from chitosan and its application as a corrosion inhibitor in boat-building carbon steel BIS2062. Appl. Nanosci. 2020, 10, 1061-1071. [CrossRef]

28. Ren, X.; Liang, W.; Wang, P.; Bunker, C.E.; Coleman, M.; Teisl, L.R.; Cao, L.; Sun, Y.P. A new approach in functionalization of carbon nanoparticles for optoelectronically relevant carbon dots and beyond. Carbon N. Y. 2019, 141, 553-560. [CrossRef]

29. Sun, Y.P.; Zhou, B.; Lin, Y.; Wang, W.; Fernando, K.A.S.; Pathak, P.; Meziani, M.J.; Harruff, B.A.; Wang, X.; Wang, H.; et al. Quantum-sized carbon dots for bright and colorful photoluminescence. J. Am. Chem. Soc. 2006, 128, 7756-7757. [CrossRef]

30. Sekiya, R.; Uemura, Y.; Murakami, H.; Haino, T. White-Light-Emitting Edge-Functionalized Graphene Quantum Dots. Angew. Chem. 2014, 126, 5725-5729. [CrossRef]

31. Cayuela, A.; Soriano, M.L.; Carrillo-Carrión, C.; Valcárcel, M. Semiconductor and carbon-based fluorescent nanodots: The need for consistency. Chem. Commun. 2016, 52, 1311-1326. [CrossRef] [PubMed]

32. D'Amora, M.; Giordani, S. Carbon Nanomaterials for Nanomedicine. Smart Nanopart. Biomed. 2018, 2018, 103-113. [CrossRef]

33. Abu Rabe, D.I.; Al Awak, M.M.; Yang, F.; Okonjo, P.A.; Dong, X.; Teisl, L.R.; Wang, P.; Tang, Y.; Pan, N.; Sun, Y.P.; et al. The dominant role of surface functionalization in carbon dots' photo-activated antibacterial activity. Int. J. Nanomed. 2019, 14, 2655-2665. [CrossRef] [PubMed]

34. Bi, R.; Zhang, Q.; Zhang, R.; Su, Y.; Jiang, Z. Thin film nanocomposite membranes incorporated with graphene quantum dots for high flux and antifouling property. J. Memb. Sci. 2018, 553, 17-24. [CrossRef]

35. Khairkar, S.R.; Pansare, A.V.; Shedge, A.A.; Chhatre, S.Y.; Suresh, A.K.; Chakrabarti, S.; Patil, V.R.; Nagarkar, A.A. Hydrophobic interpenetrating polyamide-PDMS membranes for desalination, pesticides removal and enhanced chlorine tolerance. Chemosphere 2020, 258, 127179. [CrossRef] [PubMed]

36. Atkinson, A.J.; Wang, J.; Grzebyk, K.; Zhang, Z.; Jung, D.; Zeng, D.; Pollard, A.; Gold, A.; Coronell, O. Scalable fabrication of anti-biofouling membranes through 2-aminoimidazole incorporation during polyamide casting. J. Memb. Sci. 2019, 579, 151-161. [CrossRef]

37. Firouzjaei, M.D.; Seyedpour, S.F.; Aktij, S.A.; Giagnorio, M.; Bazrafshan, N.; Mollahosseini, A.; Samadi, F.; Ahmadalipour, S.; Firouzjaei, F.D.; Esfahani, M.R.; et al. Recent advances in functionalized polymer membranes for biofouling control and mitigation in forward osmosis. J. Memb. Sci. 2020, 596, 117604. [CrossRef]

38. Zhang, M.; Zhang, K.; De Gusseme, B.; Verstraete, W. Biogenic silver nanoparticles (bio-Ag 0) decrease biofouling of bio-Ag 0/PES nanocomposite membranes. Water Res. 2012, 46, 2077-2087. [CrossRef]

39. Chen, H.; Wu, J.; Wu, M.; Jia, H. Preparation and antibacterial activities of copper nanoparticles encapsulated by carbon. New Carbon Mater. 2019, 34, 382-389. [CrossRef]

40. Pasmore, M.; Todd, P.; Smith, S.; Baker, D.; Silverstein, J.A.; Coons, D.; Bowman, C.N. Effects of ultrafiltration membrane surface properties on Pseudomonas aeruginosa biofilm initiation for the purpose of reducing biofouling. J. Memb. Sci. 2001, 194, 15-32. [CrossRef] 
41. Leong, J.X.; Daud, W.R.W.; Ghasemi, M.; Liew, K.B.; Ismail, M. Ion exchange membranes as separators in microbial fuel cells for bioenergy conversion: A comprehensive review. Renew. Sustain. Energy Rev. 2013, 28, 575-587. [CrossRef]

42. Al-Gharabli, S.; Al-Omari, B.; Kujawski, W.; Kujawa, J. Biomimetic hybrid membranes with covalently anchored chitosan-Material design, transport and separation. Desalination 2020, 491, 114550. [CrossRef]

43. Fu, J.; Ji, J.; Yuan, W.; Shen, J. Construction of anti-adhesive and antibacterial multilayer films via layer-by-layer assembly of heparin and chitosan. Biomaterials 2005, 26, 6684-6692. [CrossRef] [PubMed]

44. Zheng, B.; Wang, J.; Wang, F.B.; Xia, X.H. Synthesis of nitrogen doped graphene with high electrocatalytic activity toward oxygen reduction reaction. Electrochem. Commun. 2013, 28, 24-26. [CrossRef]

45. Benn, M.H.; Jones, A.S. 761. Glycosylureas. Part I. Preparation and some reactions of D-glucosylureas and D-ribosylureas. J. Chem. Soc. 1960, 3837-3841. [CrossRef]

46. McKay, M.J.; Nguyen, H.M. Recent developments in glycosyl urea synthesis. Carbohydr. Res. 2014, 385, 18-44. [CrossRef]

47. Jridi, M.; Hajji, S.; Ayed, H.B.; Lassoued, I.; Mbarek, A.; Kammoun, M.; Souissi, N.; Nasri, M. Physical, structural, antioxidant and antimicrobial properties of gelatin-chitosan composite edible films. Int. J. Biol. Macromol. 2014, 67, 373-379. [CrossRef]

48. Kundu, S.; Xia, W.; Busser, W.; Becker, M.; Schmidt, D.A.; Havenith, M.; Muhler, M. The formation of nitrogen-containing functional groups on carbon nanotube surfaces: A quantitative XPS and TPD study. Phys. Chem. Chem. Phys. 2010, 12, 4351-4359. [CrossRef]

49. Wang, W.; Zeng, Z.; Zeng, G.; Zhang, C.; Xiao, R.; Zhou, C.; Xiong, W.; Yang, Y.; Lei, L.; Liu, Y.; et al. Sulfur doped carbon quantum dots loaded hollow tubular g-C3N4 as novel photocatalyst for destruction of Escherichia coli and tetracycline degradation under visible light. Chem. Eng. J. 2019, 378, 122132. [CrossRef]

50. Shang, J.; Ma, L.; Li, J.; Ai, W.; Yu, T.; Gurzadyan, G.G. The origin of fluorescence from graphene oxide. Sci. Rep. $2012,2,792$. [CrossRef]

51. Tetsuka, H.; Asahi, R.; Nagoya, A.; Okamoto, K.; Tajima, I.; Ohta, R.; Okamoto, A. Optically tunable amino-functionalized graphene quantum dots. Adv. Mater. 2012, 24, 5333-5338. [CrossRef] [PubMed]

52. Sandeep Kumar, G.; Roy, R.; Sen, D.; Ghorai, U.K.; Thapa, R.; Mazumder, N.; Saha, S.; Chattopadhyay, K.K. Amino-functionalized graphene quantum dots: Origin of tunable heterogeneous photoluminescence. Nanoscale 2014, 6, 3384-3391. [CrossRef] [PubMed]

53. Cushing, S.K.; Li, M.; Huang, F.; Wu, N. Origin of strong excitation wavelength dependent fluorescence of graphene oxide. ACS Nano 2014, 8, 1002-1013. [CrossRef] [PubMed]

54. Hua, X.W.; Bao, Y.W.; Wang, H.Y.; Chen, Z.; Wu, F.G. Bacteria-derived fluorescent carbon dots for microbial live/dead differentiation. Nanoscale 2017, 9, 2150-2161. [CrossRef] [PubMed]

55. Jiang, Y.W.; Gao, G.; Zhang, X.; Jia, H.R.; Wu, F.G. Antimicrobial carbon nanospheres. Nanoscale 2017, 9, 15786-15795. [CrossRef] [PubMed]

56. Liu, J.; Lu, S.; Tang, Q.; Zhang, K.; Yu, W.; Sun, H.; Yang, B. One-step hydrothermal synthesis of photoluminescent carbon nanodots with selective antibacterial activity against Porphyromonas gingivalis. Nanoscale 2017, 9, 7135-7142. [CrossRef]

57. Dizaj, S.M.; Lotfipour, F.; Barzegar-Jalali, M.; Zarrintan, M.H.; Adibkia, K. Antimicrobial activity of the metals and metal oxide nanoparticles. Mater. Sci. Eng. C 2014, 44, 278-284. [CrossRef] 